\title{
Foundation and Principles of Music Education: Technique versus Musicality: Does Fast Technique Surpass Slow Musicality?
}

\author{
Ahmet SÖNMEZLER, DMA \\ Assistant Professor, Chair \\ Girne American University \\ Music Teaching Department \\ Kyrenia, Cyprus
}

\begin{abstract}
This study attempts to find out if fast technical piece of music surpass slow and musical piece of music among professional musicians. Eventhough musical appreciation and admiration preferences are seen as the consequences of mere subjectivity, there have been many instances where non-music majors have considered the fast technique dominated players as better or more talented than the slower but more musical players. It has been questionable on the other side whether such considerations by non-music majors are displayed by professional music majors as well, or not. Musicality is the art of expression that is only achievable via technical competency and dexterity where the technique is the aspects of skillful physical movements needed to interpret music. A survey conducted among eight professional music majors where several questions have been raised between three compositions including, A la Antiqua by Ernesto Lecuona, Etude No. 2 by Villa-Lobos, and Sonata in E minor by Niccolo Paganini.
\end{abstract}

Keywords: Music, education, technique, musicality, Barrueco

\section{Introduction}

Regardless of the main musical and technical priorities starting from the Middle Ages towards the 21st century, musicians, performers, and instrument makers must have meticulously thought about the essential technical and musical improvements that they have provided us enormous varieties of musical repertoire, stylistics, genres, forms, textures, and instruments along this timeline. However, with the varying abilities and tastes of all human beings, the main focus of the musical and technical assimilations is shifted to certain appreciation, interest, and judgement levels between listeners. Eventhough such appreciation and admiration preferences are seen as the consequences of mere subjectivity, there have been many instances where non-music majors have considered the fast technique dominated players as better or more talented than the slower but more musical players. However, it has also been questionable on the other side whether such considerations are displayed by music majors aswell or not. Consequently, no matter how subjective the individual perspectives might be (which I believe that they still need to be governed by valid reasons and evidence), I will attempt to demonstrate that musicality and technicality are two inseparable trends of music education in the field of performance where the unification of both is the ultimate goal that may lead towards the exceptional performance career. I would like to start my discussion with raising specific questions that will help defining its primary sections that will hopefully lead us towards reasonable consequences with the further survey analysis.

\subsection{What does musicality mean?}

Musicality means the art of expression that is only achievable via technical competency and dexterity. For instance; a very consistent and smooth Crescendo (gradually getting louder) with a desirable tone color can only be achieved with a precise and steady articulation combined with the gradual arrangement of the tension for increasing the volume. Furthermore, a very efficient Legato (attached) or Staccato (detached) can only be achieved with the competent technique of timing of the articulation toward stopping or attaching several notes to one another with a seemingless continuous attack. Musicality includes any further approach of interpretation beyond the mere presence and representation of musical notes. Musicality is meaningful and descriptive. 
It is a pronunciation of musical notes where performers can bring both the composer's and their personal ideas forward and reach to their listeners and express themselves. It serves as an adjective within the musical context. Musicality consists of tone, dynamics, color, timbre, articulation, phrasing, rubato and inflections.

\subsection{What does technique mean?}

Technique means the aspects of skillful physical movements needed to interpret music. Those aspects (which we feel that we possess in ourselves without the actual movement) are accuracy, control, velocity, coordination, tension, relaxation, consistency, endurance, execution, articulation, strength next to the exact physical movements (physical movements that we can actually do) including, flexion, extension, abduction, adduction, stretches, squeezes, arch, deviation, rotation, lateral movement etc. Any healthy average human body naturally possesses all of these aspects of physical movements though within certain extents. For instance, some people might possess physical movements with extreme dimensions such as twisting the thump far backwards for instance. Nearly all of the aspects of skillful physical movements can significantly be developed with careful insight, approach, and practice.

\section{Arguments}

\subsection{Can anyone play musical?}

Based on the listener's subjective analysis together with their musical background and education, some performers may very well be considered as musical players (even if they are not a musical player) where at the same time the same performer may not be considered as a musical player for others. However, since both evaluation and aquisition of musicality may need many years of training, practice, and experience, it is quite convenient to draw a conclusion that not everyone can play musical. Performers need to have adequate technique to be able to bring out the best of musical characteristics. They need to understand and feel the music and musicality. Musicality requires ability to be transferred and to convince the listeners regarding what the performers are musicaly attempting to do. Musicality needs to make sense.

\subsection{Can anyone play fast and technical?}

Apart from the listener's subjective analysis, musical background and education which I have defined at the beginning of the previous paragraph, not everyone can play fast and technical either. It may be easier for some players and may not be for the others and interestingly some players can easily aquire speed without properly understanding the movements, patterns, fingerings, and certain concepts. It usually requires lot of practice and repetition. The placement of the physical activities and notes in time is much more greater and rapid compare to slow playing.

\subsection{Can anyone play slow?}

Perhaps anyone can play slow. There is much more time to think, control, and implement most of the musical and technical ideas. Why would fast technique attract listeners? The fast technique has a greater mobility which helps to keep the listeners awake. It has show off. Show off forces the limits and expands the boundaries of human's nature of capability (flying fingers across the fingerboard). The fast technique seems and feels difficult, unreachable, therefore impossible, therefore greatly admirable. It displays apparent and vivid virtuosity and facility versus musicality which was mentioned earlier that it may need a lot of training to be able to understand the presented musical ideas, characteristics, expressions, phrases, inflections, contrasts, and timings. The fast technique is easily recognizable. For instance, a single fast scale can demonstrate the technical capability of certain performer where a single use of vibrato may not suggest a musical ability for another.

\subsection{Why would slow musicality attract listeners?}

Slow musicality tends to be expressive and emotional. It relaxes the human body and mind. It caresses the human spirit and gives freedom to people's thoughts. The slow placement of the both musical notes and physical movements in time makes them easily traceable and understandable.

Below is the overview of survey that was applied to eight professional musicians who are studying at the Peabody Conservatory of the Johns Hopkins University in USA. (See the below Table No. 1) 
Table No. 1:

\begin{tabular}{|l|l|l|l|}
\hline Questions: & 1.) A la Antiqua & 2.) Etude \#2 & 3.) Sonata in E minor \\
\hline $\begin{array}{l}\text { 1.) Which player is the } \\
\text { most technical? }\end{array}$ & 0 votes (\%0) & 6 votes (\%75) & votes (\%25) \\
\hline $\begin{array}{l}\text { 2.) Which player is the } \\
\text { most musical? }\end{array}$ & 5 votes (\%62.5) & 0 votes (\%0) & 3 votes (\%37.5) \\
\hline $\begin{array}{l}\text { 3.) Which player is the } \\
\text { most technical as well as } \\
\text { musical? }\end{array}$ & 0 votes (\%0) & 0 votes (\%0) & 8 votes (\%100)* \\
\hline $\begin{array}{l}\text { 4.) Which player is more } \\
\text { talented? Draw your best } \\
\text { selection from the } \\
\text { questions \#1 and \#2. }\end{array}$ & 3 votes (\%37.5) & 1 vote $(\% 12.5)$ & 2 votes $(\% 25)$ \\
\hline $\begin{array}{l}\text { 5.) Which player did you } \\
\text { like the most? }\end{array}$ & 3 votes $(\% 37.5)$ & 0 votes $(\% 0)$ & 5 votes $(\% 62.5)$ \\
\hline
\end{tabular}

In order to make this survey very efficient, I have chosen three explicit musical examples to be able to bring the participants onto a very close ground level that their best selections could derive from. Moreover, I have chosen the same performer, Manuel Barrueco, for the three musical examples to minimize the possible conflicts between the individual performing styles of different performers. The first listening example that I have specifically chosen to display a slow musicality, A la Antiqua, was selected as the most musical performance by the majority of participants. The second example Etude \#2 which was again deliberately chosen this time to display fast and high technicality was selected as the most technical. The final listening example was the Sonata in E minor where its performance was selected as the most technical as well as musical by all of the eight participants (\%100 vote). The emergent results for the first three questions demonstrate that the majority of the participants were brought onto a very close, if not the same, intended ground level regarding which listening was the most musical, technical or the both. Eventhough two of the participants did not have a selection for the question number four, the performance of A la Antiqua (listening Example \#1) which was selected as the most musical, was also selected as more talented between the three performances. One very important point to remember in this survey is that these three examples were only listenings. They did not appeal to visual judgements (except for the participants who might have imagined the real performances of these listening examples) which will definitely be the next step in this specific field that will be based on the exact same questions and intent in another survey. The final question of the survey was raised to demonstrate that musicality and technicality are two inseparable trends of music education in the field of performance where the unification of both is the one that is appreciated the most that may lead towards the exceptional performance career. Consequently, the survey results of the last question demonstrate that Sonata in E minor (the composition that its performance was selected as the most technical as well as musical performance) was selected as the favorite by the majority of the participants.

\section{Conclusion}

In conclusion, in this small survey, my main intention was to find out if fast played technical piece of music surpass slow and musical played piece of music between the educated professional musicians. Further more, another question was if the most technical and musical player/performance was going to be the most appreciated between the majority of professional listeners. Hence, the latter part of the question \#4 raised to direct the listeners to make a distinction between the most musical and the most technical performance that would help to identify if fast technique surpass slow musicality in their address to hearing. Moroever, the question \#5 was raised to identify if the most technical as well as musical performer was going to be the one that is appreciated the most. The above results demonstrate that the majority of the subjects (participants) of this survey were unanimous that fast technique does not surpass slow musicality in the way that they appeal to hearing, and both the technical and musical performance is the one that gains the listener's appreciation at the most. To sum up, the musicality and technicality are two inseparable trends of music education in the field of performance where the unification of both is the ultimate goal that may lead towards the exceptional performance career. 


\section{References}

Abeles, H. F., Hoffer, C. R. and Klotman, R. H. (1995). Foundations of Music Education $2^{\text {nd }}$. ed. Belmont, CA: Thomson Schirmer.

Barrueco, M. (1997). Etude No. 2. On Brouwer, Villa-Lobos and Orbon [CD]. US: EMI Classics. Barrueco, M. (1999). A La Antiqua. On Cuba [CD]. US: EMI Classics.

Barrueco, M. (2011). Sonata in E minor, Op. 3 No. 6. On Classical Guitar for a Romantic Evening [CD]. US: Suite 102.

Shearer, A. (1990). Learning the Classical Guitar Part 1. Pacific, MO: Mel Bay.

Shearer, A. (1991). Learning the Classical Guitar Part 3: Interpretation and Performance Development. Pacific, MO: Mel Bay.

Tennant, S. Pumping Nylon: The Classical Guitarist's Technique Handbook. US: Alfred Publishing. Wingell, R. J. and Herzog, S. (2001). Introduction to Research in Music. Upper Saddle River: NJ: Prentice Hall. 